\title{
Use of intravenous tocilizumab in pregnancy (1) for severe coronavirus disease 2019 pneumonia: two case reports
}

\author{
Shazia Abdullah", Nihal Bashir and Nageena Mahmood
}

\begin{abstract}
Background: Tocilizumab, an interleukin-6 inhibitor is part of many international guidelines for the management of cytokine storm associated with severe coronavirus disease 2019 with observed improvements. However, this drug is not recommended during pregnancy owing to the lack of safety data. Restriction of such medication use makes the management of coronavirus disease 2019 in pregnant women more challenging. Pregnant women are more likely to deteriorate from respiratory infections because of the immunological changes during pregnancy and the hypoxic compromise. We report the use of tocilizumab in two pregnant patients who developed severe coronavirus disease 2019 with a successful outcome. To date, there have not been any published data on tocilizumab use in pregnancy for cytokine storm syndrome associated with coronavirus disease 2019.
\end{abstract}

Case presentations: In 2020, two pregnant women of Asian origin in the last trimester of pregnancy were admitted to our hospital with severe coronavirus disease 2019. Their clinical condition progressed rapidly despite maximum supportive treatments. Blood testing in the second week of illness showed rising ferritin and interleukin-6 levels, indicating the possibility of cytokine storm syndrome. Both developed respiratory failure necessitating mechanical ventilation. Due to their critical clinical condition and lack of response to supportive treatment, a decision was made to use intravenous tocilizumab therapy. Both were treated with one intravenous infusion of tocilizumab and had a successful outcome. They were extubated later and gradually weaned off supplemental oxygen. The first patient continued with her pregnancy during the hospital stay with normal fetal scans. The second patient needed an emergency cesarean section and delivered a healthy infant.

Conclusion: In critical clinical situations, tocilizumab may have a role in managing coronavirus disease 2019 related cytokine storm during pregnancy.

Keywords: Tocilizumab, COVID-19, Pregnancy, Pneumonia, Cytokine storm, Case report

\section{Introduction}

The coronavirus disease 2019 (COVID-19) pandemic has affected more than 180 million people worldwide since its first identification in Wuhan, China in December 2019 [1].

The high-risk groups generally reported in the literature include patients of advanced age and those with

*Correspondence: shaziaabdullah05@gmail.com

Sheikh Khalifa Medical City, Abu Dhabi, UAE comorbidities such as obesity, hypertension, diabetes mellitus, and chronic respiratory and cardiovascular diseases [2].

During the H1N1 influenza pandemic of 2009, pregnant women had a higher rate of hospitalization and mortality from influenza than the general population $[3$, 4].

Thus, as a precautionary measure for COVID-19, pregnancy had been categorized in the moderate- and highrisk groups by the UK's Chief Medical Officer in March original author(s) and the source, provide a link to the Creative Commons licence, and indicate if changes were made. The images or other third party material in this article are included in the article's Creative Commons licence, unless indicated otherwise in a credit line to the material. If material is not included in the article's Creative Commons licence and your intended use is not permitted by statutory regulation or exceeds the permitted use, you will need to obtain permission directly from the copyright holder. To view a copy of this licence, visit http://creativecommons.org/licenses/by/4.0/. The Creative Commons Public Domain Dedication waiver (http://creativeco mmons.org/publicdomain/zero/1.0/) applies to the data made available in this article, unless otherwise stated in a credit line to the data. 
2020 as well as the Centers for Disease Control and Prevention $(\mathrm{CDC})[5,6]$.

Immunological changes during pregnancy, particularly in the third trimester, make women more susceptible to severe symptoms from viral infections and hypoxic compromise, as shown in studies from the previous severe acute respiratory syndrome (SARS) and Middle East respiratory syndrome (MERS) outbreaks [7].

Certain antiviral treatments such as favipiravir and camostat, and immunomodulatory treatments such as tocilizumab and anakinra, are not routinely used for COVID-19 treatment in pregnant women, making patient management more challenging [8].

We report two cases of pregnant women admitted to our facility with COVID-19 pneumonia who deteriorated rapidly despite advanced supportive treatment and needed tocilizumab therapy during the pregnancy. To date, there is only one published case report of tocilizumab use for COVID-19 illness during pregnancy, where it was used for cardiomyopathy associated with COVID-19 [9].

\section{Case 1}

A 29-year-old Asian lady with no previous significant past medical history presented in May 2020 to the maternity unit of our facility with a 5-day history of fever, cough, breathlessness, and diarrhea.

She was 24 weeks pregnant (gravida 4, para 3 with three previous caesarean sections). She was a nonsmoker and did not consume any alcohol. She was not taking any regular medications. On admission, she had a fever of $37.7{ }^{\circ} \mathrm{C}$, blood pressure of $90 / 54 \mathrm{mmHg}$, and pulse of 115 beats per minute. She was found to be in mild respiratory distress with a respiratory rate of 20 breaths per minute, and oxygen saturation was $94 \%$ on room air.

Her initial chest X-ray (CXR) (Fig. 1A) showed extensive and bilateral patchy opacification suggestive of COVID-19 illness. She tested positive for severe acute respiratory syndrome coronavirus 2 (SARS-CoV-2) on Real-time polymerase chain reaction (RT-PCR) on nasopharyngeal swab. Blood tests revealed normal renal and liver function tests, normal Hemoglobin $(\mathrm{Hb})$ of $128 \mathrm{mg} /$ $\mathrm{dl}$, and normal platelets and white cell count including differentials. Her C-reactive protein (CRP) and

Table 1 Blood test results on admission

\begin{tabular}{lll}
\hline Blood test (normal range and units) & Case 1 & Case 2 \\
\hline White blood cell count $\left(4.5-11 \times 10^{9} / \mathrm{L}\right)$ & 5.0 & 9.9 \\
Neutrophils $\left(1.8-7.7 \times 10^{9} / \mathrm{L}\right)$ & 4.04 & 6.98 \\
Lymphocytes $\left(1.5-4 \times 10^{9} / \mathrm{L}\right)$ & 0.72 & 2.15 \\
Platelet count $\left(140-400 \times 10^{9} / \mathrm{L}\right)$ & 121 & 265 \\
Hemoglobin $(117-155 \mathrm{~g} / \mathrm{L})$ & 128 & 115 \\
Lactate dehydrogenase $(135-214 \mathrm{IU} / \mathrm{L})$ & 424 & 174 \\
Ferritin $(15-150 \mu \mathrm{g} / \mathrm{L})$ & 282 & 42 \\
D-Dimer $(<0.5 \mu \mathrm{g} / \mathrm{ml})$ & 0.86 & 1.09 \\
Fibrinogen $(2-4 \mathrm{~g} / \mathrm{L})$ & 4.24 & 6.72 \\
Creatinine $(44-80 \mathrm{mmol} / \mathrm{L})$ & 45 & 31 \\
Alanine transferase $(<41 \mathrm{units} / \mathrm{L})$ & 55 & 13 \\
Aspartate transferase $(<40 \mathrm{units} / \mathrm{L})$ & 64 & 19 \\
Albumin $(35-52 \mathrm{~g} / \mathrm{L})$ & 19 & 20 \\
CRP $(<5 \mathrm{mg} / \mathrm{L})$ & 51 & 60 \\
Procalcitonin $(<0.5 \mathrm{ng} / \mathrm{ml})$ & 0.26 & 0.06 \\
Interleukin $6(<7 \mathrm{pg} / \mathrm{ml})$ & 96 & 28.4 \\
\hline
\end{tabular}

CRP, C-reactive protein; $\mathrm{g} / \mathrm{L}$, grams/litre; $\mu \mathrm{g} / \mathrm{L}$, micrograms/litre; $\mathrm{mg} / \mathrm{l}$, milligram/ litre; $\mathrm{mmol} / \mathrm{L}$, millimole/litre; $\mathrm{ng} / \mathrm{ml}$, nanogram/millilitre; $\mathrm{pg} / \mathrm{ml}$, picogram/ millilitre; IU/L, international unit/litre

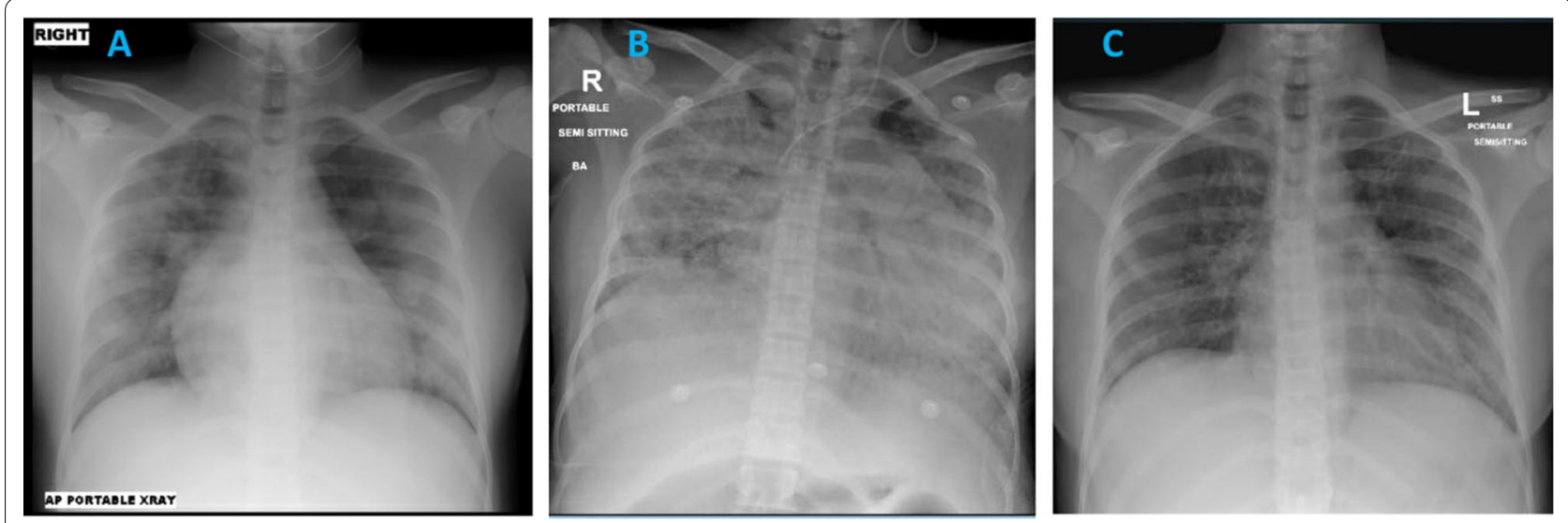

Fig. 1 A Day 1 CXR showing extensive bilateral patchy pacification suggestive of COVID-19. B Day 5 CXR showing progression of the bilateral extensive widespread consolidation in the lungs. Left internal jugular line with the tip in the distal superior vena cava (SVC). C Day 28 CXR showing significant improvement in the bilateral patchy opacification 
interleukin-6 (IL6) levels were raised at $51 \mathrm{mg} / \mathrm{L}$ and $96 \mathrm{pg} / \mathrm{ml}$, respectively. Her D-dimer level was $0.86 \mu \mathrm{g} / \mathrm{ml}$ and fibrinogen $4.2 \mathrm{~g} / \mathrm{L}$ (Table 1 ).

She was started on supplemental oxygen, hydroxychloroquine $400 \mathrm{mg}$ twice daily, intravenous ceftriaxone $1000 \mathrm{mg}$ twice daily, subcutaneous enoxaparin $40 \mathrm{mg}$ once daily, lopinavir-ritonavir $80 \mathrm{mg}-20 \mathrm{mg}$, two tablets twice daily, hydroxychloroquine $400 \mathrm{mg}$ twice daily, and acetylcysteine $600 \mathrm{mg}$ orally twice daily as per the local guidelines for COVID-19 management. Her oxygen saturation continued to drop, and after 24 hours of admission, she was on $8 \mathrm{~L} /$ minute of oxygen via face mask and managed in high-dependency unit.

By day 5 of admission, there was no clinical improvement. She still required respiratory support in the form of high-flow oxygen $40 \mathrm{~L} /$ minute and was showing signs of respiratory failure on arterial blood gases (ABGs), which revealed a $\mathrm{pH}$ of $7.45, \mathrm{pO}_{2}$ of $55 \mathrm{mmHg}$, and $\mathrm{pCO}_{2}$ of $23 \mathrm{mmHg}$. Her chest X-ray (Fig. 1B) showed marked progression. In addition, she had become restless. Proning was proving difficult, and she was started on Bilevel positive airway pressure (BIPAP). Her inflammatory markers continued to deteriorate. Her IL6 was $96 \mathrm{pg} / \mathrm{ml}$ on admission and rose to $193 \mathrm{pg} / \mathrm{ml}$. Her clinical picture was in keeping with a cytokine storm syndrome, which was not responding to her current treatment regime. A multidisciplinary meeting was called, and it was decided to administer tocilizumab $400 \mathrm{mg}$ intravenously once.

Subsequently, she was intubated and ventilated because of acute respiratory failure. Her intensive care unit (ICU) admission was complicated by candidemia, treated successfully. She improved gradually and was extubated on day 16 of admission. She had an uneventful recovery with improvement in respiratory symptoms, oxygen requirements, and CXR appearances (Fig. 1C). She was discharged from the hospital after 35 days of hospitalization. Repeated fetal ultrasound scans during admission demonstrated no evidence of fetal distress. Emergency caesarean section was not indicated during hospitalization.

She later had an elective caesarean section at 38 weeks of gestation under spinal anesthesia owing to history of previous three caesarean sections and delivered a normal male child. The initial neonatal assessment was unremarkable. No further follow-up information is available.

\section{Case 2}

A 26-year-old pregnant Asian lady at 35 weeks of gestation presented in June 2020 to the maternity unit of our hospital with 5 days of fever, dry cough, fatigue, headache, and breathlessness. She had tested positive for SARS-CoV-2 on RT-PCR on nasopharyngeal swab 5 days ago and was in self-quarantine at home. She had a background history of gestational diabetes treated with metformin $500 \mathrm{mg}$ three times a day. She was a nonsmoker and did not consume any alcohol. On admission, she appeared short of breath. She had a low-grade fever of $37.5^{\circ} \mathrm{C}$, blood pressure of $126 / 78 \mathrm{mmHg}$, and pulse of 134 beats per minute. Her respiratory rate was 30 breaths per minute, and oxygen saturation was $94 \%$ on room air, improving to $99 \%$ on $4 \mathrm{~L} /$ minute of oxygen.

Her CXR showed bilateral patchy infiltrates (Fig. 2A). Blood tests revealed normal renal and liver function tests, low hemoglobin of $115 \mathrm{mg} / \mathrm{dl}$, and normal platelets and white cell count including differentials. Her CRP was raised at $60 \mathrm{mg} / \mathrm{L}$, and IL6 levels were $28.4 \mathrm{pg} / \mathrm{ml}$. Her D-dimer level was $1.09 \mu \mathrm{g} / \mathrm{ml}$, and fibrinogen $6.72 \mathrm{~g} / \mathrm{L}$
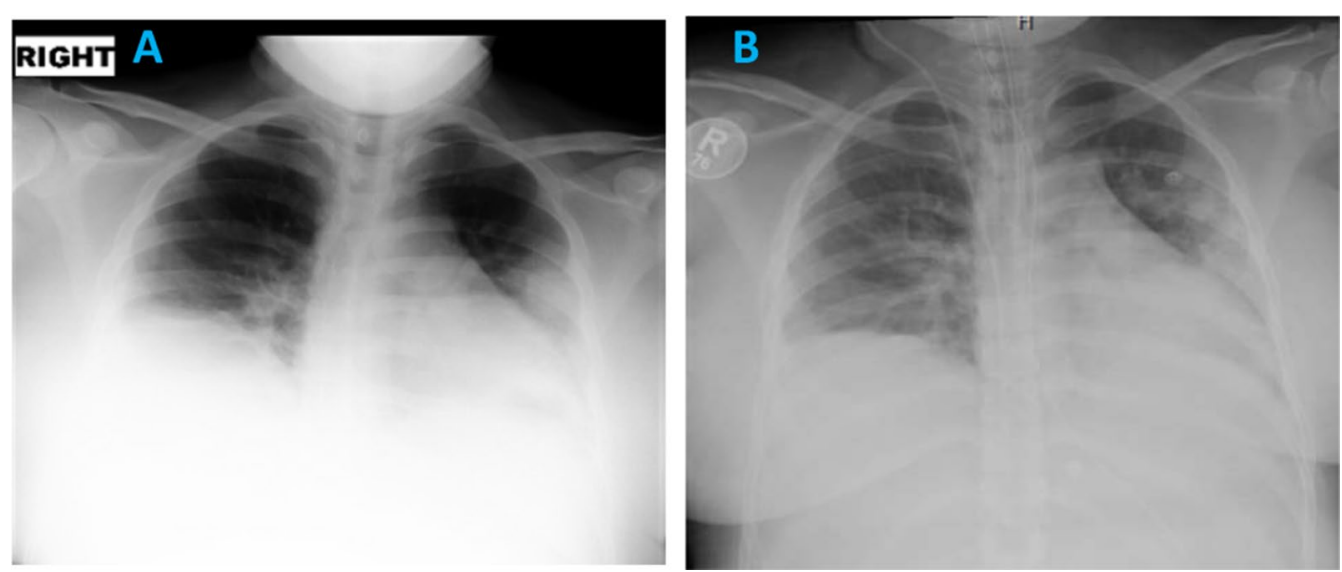

Fig. 2 A Day 1 CXR showing patchy hazy confluent airspace opacity involving left mid and lower zones with blunting of the right costophrenic angle, which may represent small right-sided pleural effusion. B Day 2 CXR showing increasing bilateral lower zonal patchy opacification. Increased bronchovesicular and interstitial lung markings 
(Table 1). The fetal scan showed normal heart beats with a breech presentation.

She was started on hydroxychloroquine $400 \mathrm{mg}$ twice daily orally, daily enoxaparin $40 \mathrm{mg}$ subcutaneously, and oral azithromycin as per our local guidelines for management of COVID-19. The azithromycin was later changed to intravenous piperacillin-tazobactam $3000 \mathrm{mg}$ intravenous four times a day. On day 2 of admission, the patient became more tachypneic with a respiratory rate of 40 breaths per minute and oxygen requirements increased to $10 \mathrm{~L} /$ minute via nonrebreather mask. Her chest X-ray showed progression of the bilateral changes due to COVID-19 pneumonia (Fig. 2B). She was therefore shifted to the high-dependency unit.

By day 4 , the patient had deteriorated further. She was receiving oxygen of $40 \mathrm{~L} /$ minute through high-flow nasal cannula with a $\mathrm{FiO}_{2} 100 \%$. Arterial blood gas testing showed a $\mathrm{pH}$ of $7.12, \mathrm{pO}_{2}$ of $104 \mathrm{mmHg}$, and $\mathrm{pCO}_{2}$ of $42 \mathrm{mmHg}$. Repeat blood testing revealed a rise in ferritin and IL6 levels indicating the possibility of cytokine storm.

As the patient was deteriorating with increasing respiratory distress, a decision was made to administer intravenous tocilizumab at a dose of $600 \mathrm{mg}$. An obstetric ultrasound showed signs of fetal distress, and therefore the baby was delivered by caesarean section. The patient's condition remained critical, and following the delivery, she was intubated and transferred to the main hospital ICU. Following delivery, she was also started on oral favipiravir $600 \mathrm{mg}$ twice daily and camostat $200 \mathrm{mg}$ three times a day orally as per the local guidelines.

She improved and was extubated 2 days later. Her oxygen saturation improved to $94 \%$ on $6 \mathrm{~L} /$ minute via nasal cannula by day 7 .

Her oxygen requirements improved further over the next few days, and the supplemental oxygen was stopped in another 5 days. She was subsequently transferred back to the maternity unit and later discharged from the hospital. The initial and 6 weeks neonatal check-up was recorded normal. No further follow-up information is available.

\section{Discussion}

We describe two cases of pregnant ladies who developed severe COVID-19 illness with evidence of acute cytokine storm. Both these patients improved clinically after use of a single dose of intravenous tocilizumab in addition to supportive treatments. Tocilizumab is generally not used during pregnancy, and to date there is only one published case report of tocilizumab use during pregnancy for severe COVID-19 illness.

During the early phase of the pandemic, clinical trial data to guide definitive treatments for COVID-19 was not available. In UAE, similar to other parts of the world, cases were approached by local and national guidelines provided by expert consensus.

A subgroup of patients with severe COVID-19 can develop an exaggerated immune response named cytokine storm syndrome that, if untreated, can lead to acute respiratory distress syndrome (ARDS) and multiple organ failure. Clinical features of this syndrome are a persistent fever, hyperferritinemia, cytopenia, and elevation of inflammatory markers such as $\mathrm{C}$-reactive protein and IL6 [10].

Timely control of the cytokine storm in its early stage through immunomodulatory therapies is the key to improving the treatment success rate and reducing the mortality rate of patients with COVID-19 [11]. Tocilizumab is one such contender and is now part of many international guidelines for use in severe-to-critical COVID-19 [12].

Tocilizumab is a humanized monoclonal antibody against both the soluble and membrane-bound interleukin-6 receptor and therefore useful when IL6 is high as part of the COVID-19-associated cytokine storm. It is recommended for the treatment of severe rheumatoid arthritis, systemic juvenile idiopathic arthritis, giant cell arteritis, and life-threatening cytokine release syndrome induced by chimeric antigen receptor T-cell therapy. In China, a retrospective study on 21 patients with severe COVID-19 pneumonia treated with intravenous tocilizumab demonstrated improvement in oxygen requirements in $75 \%$ of the treated patients [13]. Another study from Italy using intravenous tocilizumab demonstrated a significantly greater survival when compared with standard therapy in patients with severe COVID-19 [14].

Tocilizumab, however, is not recommended in pregnancy. Pregnant women are deemed just as susceptible to severe COVID-19 pneumonia as their nonpregnant peers. Once critical disease occurs, the mortality rate is $49 \%$. The only reason tocilizumab is not used in pregnancy is that there is no experience in pregnancy and, hence, safety cannot be guaranteed. Whenever clinical trials were done on tocilizumab, pregnant women were excluded. Tocilizumab is a monoclonal antibody Immunoglobulin G (IgG) that does not cross the placenta during the first trimester [15]. Thus, congenital anomalies are not associated with its use. As pregnancy advances, the transfer of tocilizumab across the placenta increases, reaching a maximum in the third trimester [16].

Reports of inadvertent use of tocilizumab indicated a slightly increased risk of preterm labor compared with the background population $[17,18]$.

The confounding factors are the seriousness of the disease itself and additional medication used. There are reports that most serious medical conditions have an 
association with preterm labor. Therefore, in the context of serious illness, there is no justification for withholding a potentially lifesaving drug in view of pregnancy. We used tocilizumab in pregnant women who developed severe COVID-19 pneumonia and critical disease with good results as witnessed in this case report. We feel strongly that pregnant women should not be denied lifesaving medication based on pregnancy alone, especially when the benefit outweighs the risk.

\section{Conclusion}

Tocilizumab may be used during pregnancy in patients who become critically unwell with cytokine storm associated with severe COVID-19 illness. The decision has to be made on a case-by-case basis by a multidisciplinary team who have experience using this drug.

\section{Abbreviations}

SARS: Severe acute respiratory syndrome; MERS: Middle East respiratory syndrome; RT-PCR: Real-time polymerase chain reaction; Hb: Hemoglobin; WCC: White cell count; CRP: C-reactive protein; IL6: Interleukin 6; ABGs: Arterial blood gases; BIPAP: Bilevel positive airway pressure; IgG: Immunoglobulin G.

\section{Acknowledgements}

We would like to thank all the nursing and medical staff in the obstetric unit, high-dependency, and intensive care unit for their dedication and care in the management of these patients.

\section{Authors' contributions}

All authors have made significant contribution to the conception, research, and writing up of the manuscript. They have modified the submitted version and have agreed both to be personally accountable for their own contributions as well as to ensure that any questions related to the accuracy or integrity of any part of the work, even ones in which the author was not personally involved, are appropriately investigated, and resolved. All authors read and approved the final manuscript.

\section{Funding}

Not applicable.

\section{Availability of data and materials}

The data supporting the findings of this case report are available within the article and its supplementary information files.

\section{Declarations}

Ethics approval and consent to participate

Not applicable

\section{Consent for publication}

Written informed consent was obtained from the patients for publication of this case report and any accompanying images. A copy of the written consent is available for review by the Editor-in-Chief of this journal.

\section{Competing interests}

The authors have no financial relationships relevant to this article to disclose. The authors have no conflicts of interest to disclose.

Received: 20 December 2020 Accepted: 12 July 2021

Published online: 07 August 2021
References

1. World Health Organization Coronavirus Disease Dashboard. https://covid 19.who.int. Accessed 11 Jun 2021.

2. Yang J, Zheng Y, Gou X, et al. Prevalence of comorbidities and its effects in patients infected with SARS-CoV-2: a systematic review and meta-analysis. Int J Infect Dis. 2020;94:91-5. https://doi.org/10.1016/j.jijid.2020.03.017.

3. Siston A. Pandemic 2009 influenza A (H1N1) virus illness among pregnant women in the United States. JAMA. 2010;303(15):1517. https://doi.org/10. 1001/jama.2010.479.

4. Creanga A, Johnson T, Graitcer S, Hartman L, Al-Samarrai T, Schwarz A, Chu S, Sackoff J, Jamieson D, Fine A, Shapiro-Mendoza C, Jones L, Uyeki T, Balter S, Bish C, Finelli L, Honein M. Severity of 2009 pandemic influenza A (H1N1) virus infection in pregnant women. Obstet Gynecol. 2010;115(4):717-26. https://doi.org/10.1097/AOG.0b013e3181d57947.

5. Centers for Disease Control and Prevention. 2020. Coronavirus Disease 2019 (COVID-19). https://www.cdc.gov/coronavirus/2019-ncov/needextra-precautions/older-adults.html.

6. NHS. 2020. Pregnancy and coronavirus (COVID-19). https://www.nhs.uk/ conditions/coronavirus-covid-19/people-at-higher-risk/pregnancy-andcoronavirus/.

7. Kourtis A, Read J, Jamieson D. Pregnancy and infection. N Engl J Med. 2014;370(23):2211-8. https://doi.org/10.1056/nejmra1213566.

8. Lexicomp. 2020.

9. Juusela A, Nazir M, Gimovsky M. Two cases of coronavirus 2019-related cardiomyopathy in pregnancy. Am J Obstetr Gynecol MFM. 2020;2(2): 100113. https://doi.org/10.1016/j.ajogmf.2020.100113.

10. Mehta P, McAuley D, Brown M, Sanchez E, Tattersall R, Manson J. COVID19: consider cytokine storm syndromes and immunosuppression. Lancet. 2020;395(10229):1033-4. https://doi.org/10.1016/S0140-6736(20) 30628-0.

11. Pedersen S, Ho Y. SARS-CoV-2: a storm is raging. J Clin Investig. 2020;130(5):2202-5. https://doi.org/10.1172/jci137647.

12. Price C, Altice F, Shyr Y, Koff A, Pischel L, Goshua G, Azar M, Mcmanus D, Chen S, Gleeson S, Britto C, Azmy V, Kaman K, Gaston D, Davis M, Burrello T, Harris Z, Villanueva M, Aoun-Barakat L, Kang I, Seropian S, Chupp G, Bucala R, Kaminski N, Lee A, LoRusso P, Topal J, Dela Cruz C, Malinis M. Tocilizumab treatment for cytokine release syndrome in hospitalized COVID-19 patients. Chest. 2020. https://doi.org/10.1016/j.chest.2020.06. 006.

13. Xu X, Han M, Li T, Sun W, Wang D, Fu B, Zhou Y, Zheng X, Yang Y, Li X, Zhang X, Pan A, Wei H. Effective treatment of severe COVID-19 patients with tocilizumab. Proc Natl Acad Sci. 2020;117(20):10970-5. https://doi. org/10.1073/pnas.2005615117.

14. Toniati P, Piva S, Cattalini M, Garrafa, et al. Tocilizumab for the treatment of severe COVID-19 pneumonia with hyperinflammatory syndrome and acute respiratory failure: a single center study of 100 patients in Brescia, Italy. Autoimmun Rev. 2020; 19(7): 102568. doi: https://doi.org/10.1016/j. autrev.2020.102568

15. Pentšuk N, van der Laan J. An interspecies comparison of placental antibody transfer: new insights into developmental toxicity testing of monoclonal antibodies. Birth Defects Res B. 2009;86(4):328-44. https:// doi.org/10.1002/bdrb.20201.

16. Tada Y, Sakai M, Nakao Y, Maruyama A, Ono N, Koarada S. Placental transfer of tocilizumab in a patient with rheumatoid arthritis. Rheumatology. 2019;58(9):1694-5. https://doi.org/10.1093/rheumatology/kez155.

17. US Food and Drug Administration, 2017. ACTEMRA (Tocilizumab) injection, for intravenous or subcutaneous use. FDA, p. 19.

18. Hoeltzenbein M, Beck E, Rajwanshi R, Gøtestam Skorpen C, Berber E, Schaefer C, Østensen M. Tocilizumab use in pregnancy: analysis of a global safety database including data from clinical trials and post-marketing data. Semin Arthritis Rheum. 2016;46(2):238-45. https://doi.org/10. 1016/j.semarthrit.2016.05.004.

\section{Publisher's Note}

Springer Nature remains neutral with regard to jurisdictional claims in published maps and institutional affiliations. 